\title{
Colour degradation of façade coatings - the effect of nanopigments incorporation
}

\author{
Nuno M. M. Ramos ${ }^{1, *}$, Andrea R. Souza ${ }^{1}$, Joana Maia ${ }^{1}$, and Ricardo M. S. F. Almeida ${ }^{1,2}$ \\ ${ }^{1}$ CONSTRUCT (LFC), Faculty of Engineering (FEUP), University of Porto, Portugal \\ ${ }^{2}$ Department of Civil Engineering, Polytechnic Institute of Viseu, Portugal
}

\begin{abstract}
The increasing interest in the use of a wide range of colours in buildings, especially dark colours, may lead to the early degradation of the façades, compromising their aesthetic and thermal performance. On the other hand, the incorporation of nanopigments with high reflectance properties can contribute to reducing the absorption of solar radiation. The nanoparticles contribute to increasing the solar reflectance of coatings, decreasing the surface temperature and improving the coating performance. This work evaluates the natural degradation of the colour of finishing coat with nanopigments in ETICS. The colour parameters were evaluated in different ETICS specimens, considering the colour black and red with and without incorporated nanopigments, under natural ageing. The colour measurement was performed according to ISO 1164-4, using a portable spectrophotometer. The results confirmed that the use of nanopigments improved the colour durability, promoting the maintenance of the colours parameters. The total colour difference was lower than the perceptible by the human eyes, even as the lower variation on chroma and hue parameters of the colours with nanopigments. In summary, the incorporation of nanoparticles in finishing coat of ETICS can contribute to increasing their durability and improve their thermal performance without compromising the aesthetic characteristics.
\end{abstract}

\section{Introduction}

The psychological importance of colour to humans has been the topic of scientific studies for over a century, and the researchers have abundantly proved that colours can activate the brain and contribute to feelings of pleasantness, variation, spaciousness, social rack and originality in architectural spaces [1]. Beyond that, the colour can also be a built environment identity or cultural character, as in La Boca in Buenos Aires, Argentina, Nyhavn in Copenhagen, Sintra in Portugal, Santorini in Greece, Burano in Italy, and Bo'kaap in Cape Town [2].

In many fields of study, colours can be seen as a quality indicator, for example, on food and medicine. However, in the constructions, the colour is usually seen as an aesthetical property. Nevertheless, with the increasing need for sustainable buildings, the colour of the façade became a relevant factor for energy consumption and durability. Façades painted with darker colours will typically be hotter than lighter façades. This temperature difference can lead to a coatings degradation rate significantly colour-dependent.

A high solar reflectance of building envelopes, therefore, tends to be adopted by designers, leading to the reduction of the colour pallet. The solar reflectance can be increased with light colour coatings, or reflective membranes applied in roofs, pavements or walls [3]. Revel et al. [4] comments that one of the most challenging technical issues is to obtain surfaces that are dark in colour and, at the same time, stay cool under sun exposure.

The nanoparticles have been used in many materials at a various field of applications. In engineering, they have a wide variety of applications, as in building coatings to improve thermal performance. Nanoparticles with cool effect are particles with relatively high solar reflectance and high infrared emittance, reducing the surface temperature $[3,5]$.

Nanopigments with cool effect can transform any colour into a "white colour" on the near-infrared (NIR) spectrum, allowing the façades to be painted with darker colours.

Beyond a simple concept, increasing the amount of reflected solar energy, there are many technical problems mainly when highly reflecting properties and the colour maintenance have to be guaranteed in the long term [6].

The solar reflectance of cool coloured materials changes in time because dust and soil are accumulated on the materials. Studies of the durability of cool paints exposed to weathering and soiling are considered very relevant since it is a fact that the properties of paints with nanopigments tend to decay on the first years of application $[3,7,8]$.

This paper presents the results of an experimental campaign that was carried out to evaluate the durability of colour coating façades with incorporated nanopigments exposed to natural ageing.

\footnotetext{
${ }^{*}$ Corresponding author: nmmr@fe.up.pt
} 


\section{Colour analysis}

\subsection{Colour perception}

Several factors influence the colour appearance of objects, for example, the geometry of the illumination, the shape of the objects, and the reflectance properties of their materials [9].

The importance of colourimetry is to determine which stimuli will look similar to a given observer, with a specified set of colour equalisation functions, resulting in a physical colour parameter [10].

Colourimeters measure colour by tristimulus values using an optical procedure to quantify and measure the colours. The equality of the tristimulus values indicates the same colour appearance under equal irradiation and visualisation conditions, avoiding the human biological perception of the light [11].

However, to evaluate colours, beyond the tristimulus, other attributes are required to perceive and describe a colour. These attributes are lightness, chroma, and hue (Fig. 1) [12].

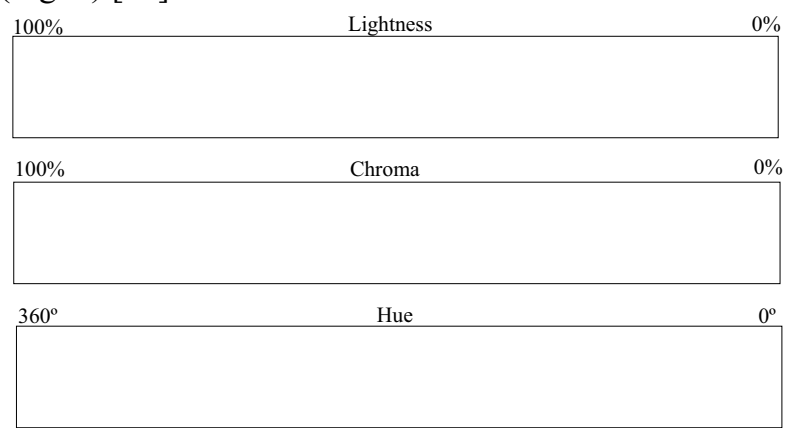

Fig. 1. Colour attributes.

The brightness is defined in terms of lightness; it is a visual perception according to which an area appears to emit or reflect more or less light. It is the variable of colour that distinguishes black from white [12].

The saturation, also known as chroma, is the purity or degree of departure from greyness; it can be described as the colourless or in other words "how coloured is the colour" [12].

Different wavelengths correspond to different hues, the shortest wavelengths appearing violet, the longest, red; the hue consists into the visible spectrum of the light. The combination of the wavelength reflection results in a visual perception according to which an object appears to be similar to one of the colours red, yellow, green or blue, or a combination of adjacent pairs in a closed ring ( 0 $\left.360^{\circ}\right)$ [12].

The tristimulus values can be obtained by transmittance measurements and converted into colours. The tristimulus coordinates are converted at colours system or colour space. The coordinates represent the lightness on the distance along the vertical axis, saturation on the radial distance away from the vertical axis, and variation in hue is the angular distance around the vertical axis [13].

Some of the interpretations of the tristimulus can be traduced into the colour spaces named: RGB, CMY, HSV and CIELab.

\subsection{CIELab system}

The Commission Internationale de l'Eclairage (CIE) established standards for the colourimetry in 1931, and since then they are widely used for measure colours. The CIELab coordinates of light referred to a CIE standard of 1976 , where the tristimulus of the light $\left(\mathrm{L}^{*}, \mathrm{a}^{*}\right.$ and $\left.\mathrm{b}^{*}\right)$ are calculated based in colour and white reflection, according to the equation of the ISO 1164-4 [14].

This CIELab system is used to describe the colour and lightness of a reflecting surface normalised to the colour of the light source (so if the reflecting surface has the same colour as the light source then $\mathrm{a}^{*}$ and $\mathrm{b}^{*}$ are zero) [9].

The $\mathrm{L}^{*} \mathrm{a}^{*} \mathrm{~b}^{*}$ coordinates lie along three mutually perpendicular axes defining a colour space (Fig. 2). The coordinates of contours $\mathrm{a}^{*} \mathrm{~b}^{*}$ correspond to the chroma and hue, and the $\mathrm{L}^{*}$ represents the lightness. The lightness coordinate varies between 0 and 100 , where zero is black, and 100 is white. The contours, vary of $-a^{*} b^{*}$ to $+a^{*} b^{*}$, where a negative $\mathrm{a}^{*}$ corresponds to a green and positive red tones, and the $b^{*}$ negative blue and the positive yellow tones [15].



Fig. 2. CIELab colour space.

There is general agreement that using the CIELab system is an improvement over using the Euclidean distance between XYZ tristimulus coordinates as a colour difference metric. The CIELab coordinates allow estimating the colour matching with a reference material by calculating the colour difference [16].

\section{Materials and methods}

\subsection{Materials}

The proposed methodology was applied to a set of ETICS specimens constituted by three distinct layers, Table 1 .

The finishing coat was applied in two distinct colours, black and red. The influence of nanopigments was assessed by adding a reflective nanopigment in the nearinfrared zone. The nanopigment is a commercial high reflectance NIR Black PBr29.

The specimens have the following designation: EB0 and EB1 (black colour) and, ER0 and ER1 (red colour), without nanopigment ("0") and with nanopigment ("1"), respectively. 
Table 1. Specimens constitution.

\begin{tabular}{|c|c|c|}
\hline \multicolumn{2}{|c|}{ Layer } & \multirow{2}{*}{$\begin{array}{l}\text { Constitution } \\
\text { Organic coating composed } \\
\text { by mineral fillers, resins in } \\
\text { aqueous dispersion, pigments } \\
\text { and specific additives } \\
\text { (antifungal and others); }\end{array}$} \\
\hline 1 & $\begin{array}{l}1 \text { Finishing } \\
\text { coating }\end{array}$ & \\
\hline$\sqrt[3]{\mid+4}$ & 2 Basecoat & $\begin{array}{l}\text { Two layers of } 1.5 \mathrm{~mm} \text { with a } \\
\text { glass fibre mesh between } \\
\text { them. Mortar based on a } \\
\text { mixture of cement, resins, } \\
\text { mineral fillers, synthetic } \\
\text { fibbers and specials additives }\end{array}$ \\
\hline & $\begin{array}{l}3 \text { Insulation } \\
\text { slab }\end{array}$ & $\begin{array}{l}\text { Expanded polystyrene - EPS } \\
\left(20 \mathrm{~kg} / \mathrm{m}^{3}\right) \text { with a thickness } \\
\text { of } 4 \mathrm{~cm}\end{array}$ \\
\hline
\end{tabular}

\subsection{Methods}

\subsubsection{Ageing cycle}

A total of 4 specimens were subjected to natural ageing for two years, being exposed on a building flat roof in Porto, Portugal. Fig. 3 shows the specimens during the exposure period.

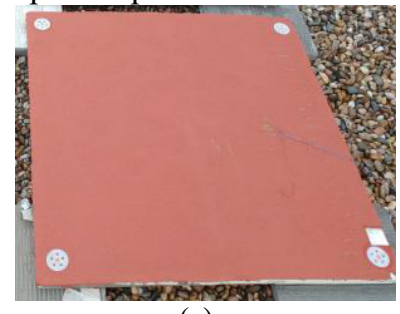

(a)



(b)
Fig. 3. Exposure condition: (a) Red specimen without nanopigments; (b) Black specimen without nanopigments.

The testing time was divided into the cycles explained in Fig. 4. The orange colour refers to the evaluation of samples exposed to natural ageing and the grey colour of unexposed specimens.

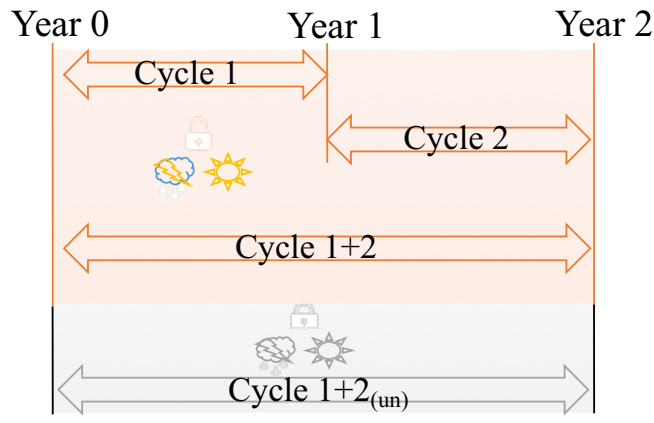

Fig. 4. Description of the ageing cycles.

The typical weather, according to the TRY Energy Plus [17], of the "in situ" test condition is presented in Fig. 5 .



Fig. 5. Typical climate conditions.

\subsubsection{Colour measurement and evaluation}

In this research, colour durability was assessed by determining the CIELab colour space measurement using a modular spectrometer. The measurements were taken into three distinct points for each samples, considering the begin and the end of the cycles..

The modular spectrometer (coupling 2 spectrometers, with distinct wavelength range: FLAME-T (UV-Vis) and FLAME-NIR (NIR) from Ocean Optics) combines light from halogen and deuterium filaments delivered through a $4.5 \mathrm{~mm}$ fibber diameter port. The optical fibber applies the beam to the sample, and a specific software reads the reflected light beam.

The software displays the reflectance spectrum, measured at $10 \mathrm{~nm}$ intervals wavelength from 190 to 1650 $\mathrm{nm}$ and the $\mathrm{L}^{*} \mathrm{a}^{*} \mathrm{~b}^{*}$ colour coordinates. All colour measurements were taken using conditions of the standard illuminant D65 and 10 degrees observer.

In this research, different colour parameters were considered, namely: lightness, chroma and hue angle parameters. The degradation can be evaluated by the total colour difference and the yellowness index.

The CIE Standard specifies the method of calculating the coordinates of the CIE $\mathrm{L}^{*} \mathrm{a}^{*} \mathrm{~b}^{*}$ colour space including correlates of lightness, chroma and hue. It includes methods for calculating Euclidean distances in this space to represent the perceived magnitude of colour difference [14].

The lightness $\left(\mathrm{L}^{*}\right)$ is an approximate measurement of luminosity, which is the property according to which each colour can be considered as equivalent to a member of the greyscale. To human eyes, a higher $\mathrm{L}^{*}$ represents a light colour and can be related to the tone, or the brightness.

The chroma $\left(\mathrm{C}^{*}\right)$ is used to determine the degree of difference of a hue in comparison to grey colour with the same lightness. Chroma is calculated using Eq. (1) [14].

$$
\mathrm{C}^{*}=\sqrt{\mathrm{a}^{* 2}+\mathrm{b}^{* 2}}
$$

The higher the chroma values, the higher the colour intensity perceived by humans. The chroma variation $(\Delta \mathrm{C})$ presents the difference in reflecting/transmit saturated light [9].

A hue angle $\left(\mathrm{h}^{*}\right)$ is the attribute according to which colours have been traditionally defined as reddish and greenish. The hue is calculated by Eq. (2) [14]. 


$$
\mathrm{h}^{*}=\tan ^{-1}\left(\frac{\mathrm{b}^{*}}{\mathrm{a}^{*}}\right)
$$

The hue is related to the differences in absorbance at different wavelengths. An angle of $0^{\circ}$ or $360^{\circ}$ represents red hue, while angles of $90^{\circ}, 180^{\circ}$ and $270^{\circ}$ represent yellow, green and blue hues, respectively. Colours with the same hue are distinguished with adjectives referring to their lightness or colourfulness, such as with "light blue", "pastel blue", "vivid blue" [11]. The total colour difference $(\Delta \mathrm{E})$ indicates the magnitude of the colour difference between the aged and the new sample. The $\Delta \mathrm{E}$ is calculated by Eq. (3) [14].

Where:

$$
\Delta E=\sqrt{\left(\Delta a^{*}\right)^{2}+\left(\Delta b^{*}\right)^{2}+\left(\Delta L^{*}\right)^{2}}
$$

$\Delta \mathrm{a}^{*}, \Delta \mathrm{b}^{*}=$ differences between the coordinates of the reference and the test in modulus;

$\Delta \mathrm{L}^{*}=$ differences between the lightness of the reference and the test in modulus.

Differences in perceivable colour, for human eyes, can be analytically classified as indicated in Table 2 [18].

Table 2. $\Delta$ E evaluation.

\begin{tabular}{|c|c|}
\hline Perceivable & Total colour difference \\
\hline Very perceptible & $\Delta \mathrm{E}>3$ \\
\hline Perceptible & $1.5<\Delta \mathrm{E}<3$ \\
\hline Almost imperceptible & $1.5<\Delta \mathrm{E}$ \\
\hline
\end{tabular}

The Yellowness Index (YI) is associated with a degradation produced by light, chemical exposure and processing. The YI is calculated by Eq. (4) [11].

$$
\mathrm{YI}=\frac{142.85 b^{*}}{L^{*}}
$$

The variation of yellowing indices $(\Delta \mathrm{YI})$ is essentially used to quantify these types of reference and test degradation in module. Where the higher the index, the higher the chemical degradation suffered by the specimen.

\section{Results and discussion}

\subsection{Colour parameters}

The colour evaluation was performed using the modular spectrophotometer reflection process. Table 3 presents the CIELab colour parameters (mean of three readings) regarding the beginning of Cycle 1 , year 0 , and at the end of the other cycles, year 1 and 2 (with and without exposure).

In year 0 , as expected, the red samples presented a higher $\mathrm{a}^{*}$ coordinate than the black samples. It was also expected that the black samples had a near-zero coordinate of $a^{*}$ and $b^{*}$. Nevertheless, no significant difference between the samples with (1) or without (0) nanopigments was found at the end of Cycle 1.

The samples without nanopigments present a lower lightness than the samples with nanopigments. This effect was also reported by Piri, Shams-Nateri and Mokhtari, [5] Coser et al. [19], Cozza et al. [18] and Revel et al. [7].

As described by Choudhury [12], the colour should also be evaluated by the combination of hue, brightness and saturation. Table 4 presents the colour parameters for chroma, hue and the yellow index.

Table 3. CIELab measurements.

\begin{tabular}{|c|c|c|c|c|c|}
\hline \multirow{2}{*}{ Year } & \multirow{2}{*}{ CIELab } & \multicolumn{4}{|c|}{ Samples } \\
\cline { 2 - 6 } & & EB0 & EB1 & ER0 & ER1 \\
\hline \multirow{3}{*}{0} & $\mathrm{~L}$ & 33.40 & 35.20 & 38.90 & 38.70 \\
\cline { 2 - 6 } & $\mathrm{a}^{*}$ & 0.50 & 1.20 & 30.70 & 28.40 \\
\cline { 2 - 6 } & $\mathrm{b}^{*}$ & -1.40 & -2.30 & 19.60 & 17.80 \\
\hline \multirow{3}{*}{1} & $\mathrm{~L}$ & 34.53 & 35.43 & 37.80 & 38.80 \\
\cline { 2 - 6 } & $\mathrm{a}^{*}$ & 0.57 & 0.90 & 29.30 & 26.40 \\
\cline { 2 - 6 } & $\mathrm{b}^{*}$ & 0.40 & -1.03 & 18.00 & 17.10 \\
\hline \multirow{3}{*}{$2 \mathrm{e}$} & $\mathrm{L}$ & 34.73 & 36.07 & 36.60 & 39.80 \\
\cline { 2 - 6 } & $\mathrm{a}^{*}$ & 0.10 & 0.07 & 27.50 & 22.80 \\
\cline { 2 - 6 } & $\mathrm{b}^{*}$ & 0.73 & -1.60 & 16.70 & 16.20 \\
\hline \multirow{3}{*}{2 un } & $\mathrm{L}$ & 32.90 & 34.20 & 39.00 & 38.20 \\
\cline { 2 - 6 } & $\mathrm{a}^{*}$ & 0.60 & 1.30 & 30.30 & 28.00 \\
\cline { 2 - 6 } & $\mathrm{b}^{*}$ & -1.00 & -1.90 & 19.60 & 18.00 \\
\hline
\end{tabular}

Table 4. Colour parameters.

\begin{tabular}{|c|c|c|c|c|c|}
\hline \multirow{2}{*}{ Year } & $\begin{array}{c}\text { Colour } \\
\text { properties }\end{array}$ & \multicolumn{4}{|c|}{ Samples } \\
\cline { 2 - 6 } & $\mathrm{C}^{*}$ & 2,5 & 6,5 & 414,9 & 345,2 \\
\hline \multirow{3}{*}{0} & $\mathrm{~h}^{*}$ & 289,7 & 297,6 & 32,6 & 32,1 \\
\cline { 2 - 6 } & $\mathrm{YI}$ & $-6,0$ & $-9,3$ & 72,0 & 65,7 \\
\hline \multirow{3}{*}{1} & $\mathrm{C}^{*}$ & 0,7 & 2,0 & 353,3 & 318,8 \\
\cline { 2 - 6 } & $\mathrm{h}^{*}$ & 35,1 & 311,1 & 31,6 & 32,9 \\
\cline { 2 - 6 } & $\mathrm{YI}^{*}$ & 7,6 & 5,2 & 4,0 & 2,7 \\
\hline \multirow{3}{*}{$2 \mathrm{e}$} & $\mathrm{C}^{*}$ & 0,6 & 2,6 & 306,4 & 285,2 \\
\cline { 2 - 6 } & $\mathrm{h}^{*}$ & 82,2 & 272,5 & 31,3 & 35,4 \\
\hline \multirow{3}{*}{2 un } & $\mathrm{YI}^{*}$ & 3,0 & $-6,3$ & 65,2 & 58,1 \\
\cline { 2 - 6 } & $\mathrm{C}^{*}$ & 1,6 & 4,9 & 414,5 & 352,0 \\
\cline { 2 - 6 } & $\mathrm{h}^{*}$ & 301,0 & 304,4 & 32,9 & 32,7 \\
\hline & $\mathrm{YI}$ & $-4,3$ & $-7,9$ & 71,8 & 67,3 \\
\hline
\end{tabular}

The $h^{*}$ indicates the reflected wavelength spectrum to define the colour by the retina cones. The angle of zero and 360 represents the red, as shown in Fig. 1. The intensity of the colour is defined by the $\mathrm{C}^{*}$. When the chroma value is zero, the eye interprets all colours as black, while high $\mathrm{C}^{*}$ values improve eye colour interpretation.

The lower values of the yellowness index (YI) indicate a reduced influence of the degradation process. It can be observed that samples with nanopigments have a lower influence than the samples without nanopigment.

The higher solar reflectance, provided by the effect of nanopigments, can lead to reducing chemical degradation by ultraviolet beams exposure. Moreover, the lower surface temperature leads to low thermal stress, reducing the internal tensions as described by Ihara et al. [3].

\subsection{Colour degradation}

The colour difference between the specimens is specified in Fig. 6. The difference is calculated for Cycle 1 (the difference between year 1 and 0 ) and Cycle 2 (the difference between year 2 and 1).

The colour change is perceptible by the human eye when $\Delta \mathrm{E}$ is higher than 3 (dashed line in Fig. 6). The results show that it is only perceptible by the human eye the variation of red colour. 


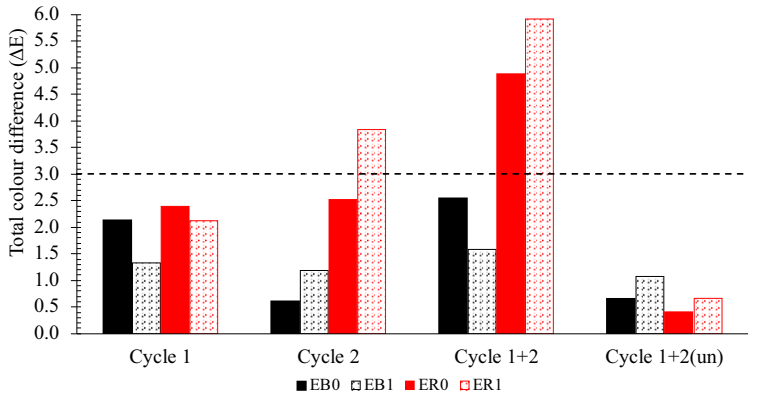

Fig. 6. Total colour difference.

The incorporation of nanopigments resulted in a lower $\Delta \mathrm{E}$ for the black colour at the end of the exposure cycle (Cycle 1+2), while the red colour had the opposite behaviour. For the exposed specimens with nanopigment, just the red colour presents the total colour difference higher than 3 after two years of exposure.

It was expected that nanopigments suffer a higher degradation in the first year, as indicated by the European Cool Roof Council [20]. Furthermore, this behaviour was not verified in this research. The degradation for the colour with nanopigments began after the second year of exposure.

The total colour difference and the lightness difference are affected by the ageing process since soiling, solar degradation (UV) and rain can affect the surface [3]. This statement can be proven by evaluating Cycle 1+2(un) in Fig. 6, where the samples under an unexposed environment have a lower colour variation.

The colour difference presents a relationship with the concentration of pigments in the paint. The samples were painted with a commercial product based on black cool pigments.

Fig. 7 presents the lightness variation as a difference between the values of $\mathrm{L}^{*}$ coordinate. Positive values indicate the colour lightning, while negative values the colour darkening.

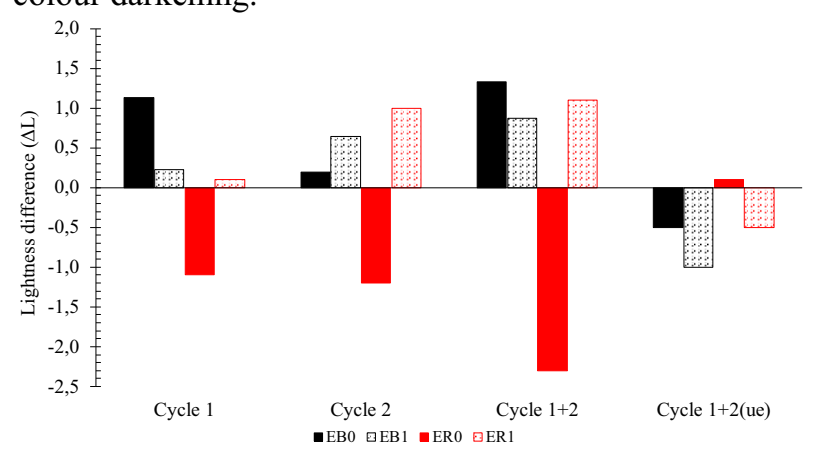

Fig. 7. Lightness difference.

The evaluation of lightness, at the end of Cycle 1, does not indicate a high variation between the colours, ranging from 33,4 to 38,70 . However, the paint without nanopigments suffered a higher difference in lightness with the ageing, by becoming lighter for black and darker for red colour.

The colours with nanopigments obtained a lesser variation in luminosity at the end of the exposure cycle (Cycle 1+2) and both colours became lighter. Considering the unexposed cycle the samples with nanopigments became darker than the without nanopigments.
According to Revel et al. [6], the increment of lightness is important for the thermal behaviour of standard samples since it increases the coating reflectance.

Some studies, such as Revel et al. [7], Ihara et al. [3], Rosso et al. [21], indicate that the colour difference is correlated to the thermal performance and reflectance for the nanopigments. Thus, nanopigment performance can be evaluated by the colour difference.

\subsection{Influence of nanopigments}

The behaviour of specimens with the incorporation of nanopigments was analysed separately for each colour. The evaluated colour properties were chroma and hue.

Fig. 8 shows the behaviour of black and Fig. 9 of the red specimens. The influence of the nanopigments is contradictory for these two colours. This behaviour can be explained based on the pigment concentration and surface roughness [7].

The chroma difference evaluates the increment of the initial chroma value. The difference of chroma indicates the purity of the colour among the ageing cycle. The high values of chroma indicate the instances of high reflectance on a range of visible light, according to Hanson [9].

For the black colour (see Fig. 8), the values of chroma difference indicate that nanopigments can contribute to the colour durability.

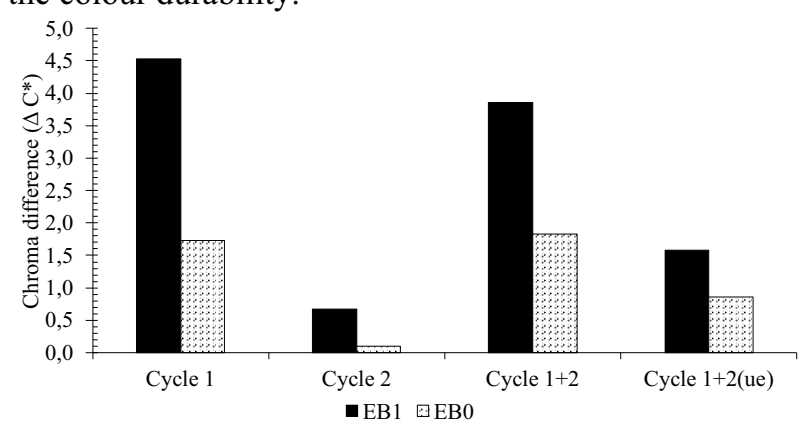

Fig. 8. Black colour properties variation.

The incorporation of nanopigments resulted in a negative influence on the chroma property of the red colour. Fig. 9 shows that their incorporation led to an increase in the chroma variation.

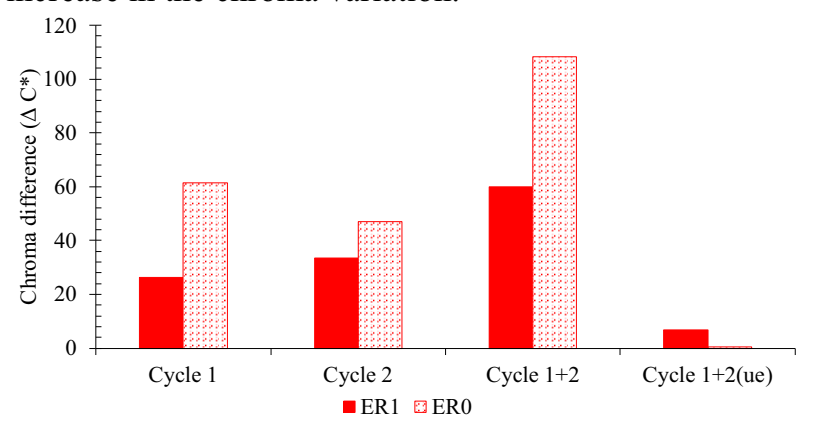

Fig. 9. Red colour properties variation.

Chroma variation, for the red colour, is related to the reflectance variation in the visible spectrum. In this case, the thermal behaviour of the cool nanopigment may have been affected, since some light colours, as orange and 
yellow, can reflect more light in the visible spectrum, as analysed by Sattar [15].

Hue is correlated with the wavelength that is reflected by the samples and the primary colour of the object [16]. The variation of hue for the same chroma and lightness indicates a variation of the reflected wavelength, and consequently a thermal performance variation.

Fig. 10 shows that the colours have a significant change on hue for the black specimen without nanopigments and a less significant change for the red one. However, the specimens with nanopigments present a constant hue in both colours.

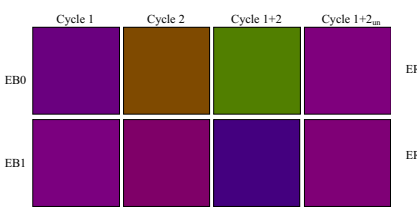

(a)

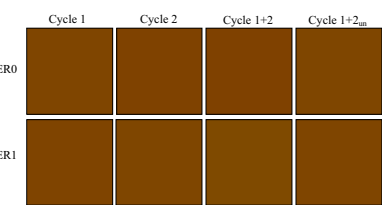

(b)
Fig. 10. Hue colour difference (a) for black (b) for red.

Fig. 11 and Fig. 12 present the ratio between the total colour difference $(\Delta \mathrm{E})$ and the variation of the yellow index $(\Delta \mathrm{YI})$, and between $\Delta \mathrm{E}$ and lightness, respectively.

The yellowness index can be described as the ratio between chemical exposure or degradation and colour. Fig. 11 shows that the coatings with nanopigments present a tendency to a linear correlation between $\Delta \mathrm{YI}$ and $\Delta \mathrm{E}$.



Fig. 11. Influence of nanopigments on yellow degradation.

As studied by Coser et al. [19], solar exposure contributes to the degradation of acrylic paint. Thus, the increment of nanopigments can protect paint films from degradation by scattering absorbed light.

The results show that the use of nanopigments ca increase the protection against degradation of the colour. Therefore, to change the colour, it is necessary to increase the exposure to degradation.

The incorporation of nanopigments was proved to be relevant to maintain the properties of the colours, which can be seen in Fig. 12, regarding the linear correlation between $\Delta \mathrm{E}$ and $\Delta \mathrm{L}$ for the coatings without nanopigments.

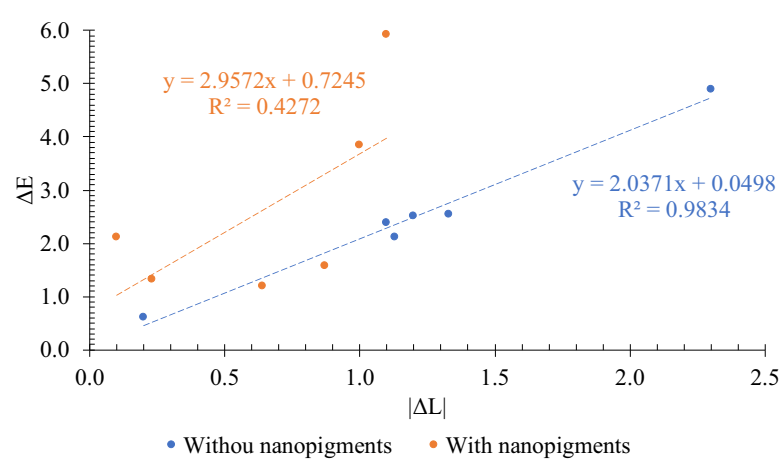

Fig. 12. Influence of nanopigments on lightness degradation.

Lightness is an important colour property to nanopigments since it can be related to the cool effect, as described by Revel et al. [6]. For the studied case, the variation of the lightness was lower for the samples with nanopigments. However, a relationship between the total colour difference and the lightness variation was not found.

\section{Conclusions}

Colour is an important parameter in the solar reflection of coatings, in which light colours have higher reflectance than the darker ones. Nanopigments can improve the reflectance of darker colours without changing the colour perception by the human eye.

The incorporation of nanopigments does not affect the composition of the colour, for both studied samples of the same colour in an initial stage. However, the results confirm that the presence of nanopigments positively affects the perception of the lightness and colour of aged finishing coat for some colours, as red colour.

The specimens with nanopigments had lower changing effect by the ageing than the ones without nanopigments. The colour changing resulted from the chroma, hue and lightness variation. Thus, the incorporation of nanopigments can protect paint films from degradation by scattering absorbed light.

Studies on the loss of optical and thermal behaviour of coatings incorporating nanopigments with cool effect demonstrated the negative influence of weather exposure. In this paper, it was confirmed that the colour is also affected by the same variables. However, the use of nanopigments results in a lower degradation than the standard colours.

This work was financially supported by Project PTDC/ECICON/28766/2017 - POCI-01-0145-FEDER-028766 funded by FEDER funds through COMPETE2020 - Programa Operacional Competitividade e Internacionalização (POCI). The authors also acknowledge to Saint-Gobain Weber to the materials supply.

\section{References}

1. J. Janssens, Nord. Arkit., 17-21 (2001).

2. F. Perry, The Gardian, (2016).

3. T. Ihara, B.P. Jelle, T. Gao, A. Gustavsen, Energy Build., 112, 184-197 (2016).

4. G.M. Revel, M. Martarelli, M. Emiliani, L. 
Celotti, R. Nadalini, A. De Ferrari, S. Hermanns, E. Beckers, G.M. Revel, E. Beckers, S. Hermanns, M. Emiliani, A. De Ferrari, L. Celotti, M. Martarelli, Sol. Energy, 105, 780-791 (2014).

5. N. Piri, A. Shams-Nateri, J. Mokhtari, Color Res. Appl., 41, 477-483 (2016).

6. G.M. Revel, M. Martarelli, M. Emiliani, A. Gozalbo, M.J. Orts, M.Á. Bengochea, L. Guaita Delgado, A. Gaki, A. Katsiapi, M. Taxiarchou, I. Arabatzis, I. Fasaki, S. Hermanns, Sol. Energy, 105, 770-779 (2014).

7. G.M. Revel, M. Martarelli, M.Á. Bengochea, A. Gozalbo, M.J. Orts, A. Gaki, M. Gregou, M. Taxiarchou, A. Bianchin, M. Emiliani, Cem. Concr. Compos., 36, 128-135 (2013).

8. K.L. Uemoto, N.M.N. Sato, V.M. John, Energy Build., 42, 17-22 (2010).

9. A.R. Hanson, em: Colour Des., Second Edi, 3-21 (2012).

10. ISO, ISO 11664 Colorumetry - Part 3: CIE tristimulus values, (2016).

11. P.B. Pathare, U.L. Opara, F.A.J. Al-Said, Food Bioprocess Technol., 6, 36-60 (2013).

12. A.K.R. Choudhury, Colour and appearance attributes, (2014).

13. R. Talbert, Paint Technology Handbook, (2008).

14. ISO, ISO 11664 Colorimetry - Part 4: CIE 1976 $L * a * b *$ Colour space, (2008).

15. S. Sattar, J. Chem. Educ., 96, 1124-1128 (2019).

16. D.H. Brainard, em: Sci. Color, 191-216 (2003).

17. EnergyPlus, (2020).

18. E.S. Cozza, M. Alloisio, A. Comite, G. Di Tanna, S. Vicini, Sol. Energy, 116, 108-116 (2015).

19. E. Coser, V.F. Moritz, A. Krenzinger, C.A. Ferreira, Polímeros, 25, 305-310 (2015).

20. K. Gobakis, H. Meier, D. Kolokotsa, A. Synnefa, R. Evans, M. Santamouris, REHVA J., 19-24 (2016).

21. F. Rosso, A. Pisello, W. Jin, M. Ghandehari, F. Cotana, M. Ferrero, Sustainability, 8, 753 (2016). 